\title{
HEZKUNTZA GRADUKO IKASLEEN AUTOKONTZEPTU ARTISTIKOA EDUCATION DEGREE STUDENTS' ARTISTIC SELF-CONCEPT
}

\section{Eneko Balerdi Eizmendi}

Mondragon Unibertsitatea

\section{Laburpena}

Ikerketa honen helburua Hezkuntza Graduko ikasleen autokontzeptu artistikoa neurtzea da. Ikerketa hau tesi bidean den ikerketa zabalago baten baitan kokatzen da eta EAEko lau Unibertsitate eta Cantabriako Unibertsitateko 1321 ikaslek hartu dute parte. Haur hezkuntza eta Lehen Hezkuntza Graduetako ikasleek erantzun diote autokontzeptu artistikoa neurtzeko diseinaturiko (AUART) galdetegiari. Autokontzeptu positiboa motibazioa eta emaitzak indartzen dituen aldagaia da, norbanakoen funtzionamendu pertsonal, sozial eta profesionalari neurri esanguratsuan eragiten baitio, hori horrela, garrantzitsua eta baloratua da hezkuntzan.

Hitz gakoak: AUTOKONTZEPTU ARTISTIKOA; HEZKUNTZA GRADUKO IKASLEA; HEZKUNTZA ARTISTIKOA; DANTZA; ANTZERKIA; MUSIKA ETA ARTE PLASTIKOAK

\section{Abstract}

The purpose of this investigation is to measure Education Degree students' artistic self-concept. This research is part of a broader thesis study and 1321 students have participated from four Universities at the Basque Autonomous Community and the University of Cantabria. Infant and Primary Education students have answered to the questionnaire designed to measure students' artistic concept (AUART). Positive self-concept is a variable that reinforces motivation and the results, because it affects in a significant extent to individuals for personal, social and professional competences and therefore it is so important and valued in education.

Key words: ARTISTIC SELF-CONCEPT; EDUCATION DEGREE STUDENT; ART EDUCATION; DANCE; DRAMA; MUSIC AND PLASTIC ARTS

\footnotetext{
Balerdi Eizmendi, Eneko. 2015. "Hezkuntza graduko ikasleen autokontzeptu artistikoa”. AusArt 3 (1): 192-204. DOI: 10.1387/ausart.14762
}

\section{AUSART}




\section{SARRERA}

Ikerketa honek Hezkuntza Graduko ikasleek arlo artistikoan dituzten jakintza eta ahalmenetan oinarrituta, euren buruarekiko eraikitako deskribapena behatuko du eta honetan eragin dezaketen aldagaien azterketa bat egingo du.

Autokontzeptu positiboak motibazioaren eta emaitzen hobekuntza eragiten ditu eta gizabanakoaren funtzionamendu pertsonal, sozial eta profesionala indartzen dituenez, garrantzitsua eta balio haundikoa da hezkuntzan (Vispoel, 1995; Esnaola, Goñi eta Madariaga, 2008). Bordenek eta Stonek (1982) diotenez, irakaslea haurraren hezkuntzan eta bizitzan eragile esanguratsuetako bat da, berak haurren irudi aldaketa eragiteko aukera du, hots, hauek jokabide aldaketak izango dituzte ondorio. Horri Naranjok (2006) dioena gehitu behar zaio: oso zaila litzatekeela irakasle batentzat bere ikasleekin gaiaren inguruan lan egitea, hauek autokontzeptu baxua izanik. Hori horrela Hezkuntza Graduko ikasleen autokontzeptua ikertzea beharrezkoa ikusi da.

Hezkuntza Graduko ikaslea, epe laburrean eskolak ematen hasiko denez, arlo artistikoaren jakintza, gaitasun eta baloreak transmititzeko prestatzen da. Europar Komunitatearen Kontseiluak (2006) etengabeko formakuntzarako oinarrizkoak diren konpententziak finkatu ditu eta Euskal Autonomi Erkidegoko Oinarrizko Hezkuntzarako Curriculumak (2007) giza eta arte kulturarako gaitasunaren garapenaren beharra jaso du: irakasleak, batetik, ikasleak kultur-jakintzak bereganatzea lortu behar du, apreziaziorako eta adierazpenerako gaitasunak garatzea bestetik, eta hirugarrenik, sormenean eta gaitasun estetikoa lantzeko borondatean oinarrituz, kultur adierazpen anitzekiko jarrera irekia izatea.

\section{AutOKONTZEPTUA}

Bere esperientzia eta ingurunearekin dituen erlazioetan oinarrituz, pertsona batek bere buruarekiko eraiki duen irudia da autokontzeptua eta berebiziko garrantzia dute giroa indartzeak zein beste esanguratsuek (Shavelson, Hubner eta Staton 1976).

Ikerketaren hastapenetan autokontzeptu unitarioaren ikusmoldea nagusitu da, William Jamesek, autokontzeptuaren teorian entzute aitortua duen lehenengo psikologoak, hiru izate ezberdindu bazituen ere: ni materiala, ni soziala eta ni espirituala. Hala defendatzen dute Brookover, Thomas eta Patterson (1964), 
Rosenberg (1965), Coopersmith (1967) edo Marx eta Winne (1978) autoreek ere ikuspegi global edo dimentsiobakarreko autokontzeptua.

Hirurogeitamargarren hamarkadatik aurrera, ordea, ikertzaileen ikuspegia aldatu egin da eta ordutik autokontzeptu orokorra niaren zatikako hautemateen multzoa dela ulertzen da. Autokontzeptua norbanakoaren esperientziaren eta garapenaren arabera etengabe hazi eta aldatzen den eraikuntza anitza eta hierarkikoa dela defendatzen dute ikerketek (Shavelson, Hubner eta Staton 1976). Autokontzeptua dimentsioaniztuna dela defendatzen duen ereduak sostengu enpiriko handiagoa jaso du eta eredu honetan oinarrituz ikertzen da autokontzeptua gaur egun.

Autokontzeptu orokorrak eremu akademikoa eta ez akademikoa batzen ditu, eremu hauen egitura dimentsionala eztabaidagai bada ere (Esnaola, Goñi eta Madariaga, 2008). Eztabaida hori egungo ikerketek elikatzen dute, egitura hierarkikoaren baitan, emaitzek mailen arteko harremanetan aniztasuna azaltzen baitute. Hala ere, tradizionalki ikerketa gehiengoak, Shavelson, Hubner eta Stantonen (1976) eredua berretsi du ikerteta gehiengoak.

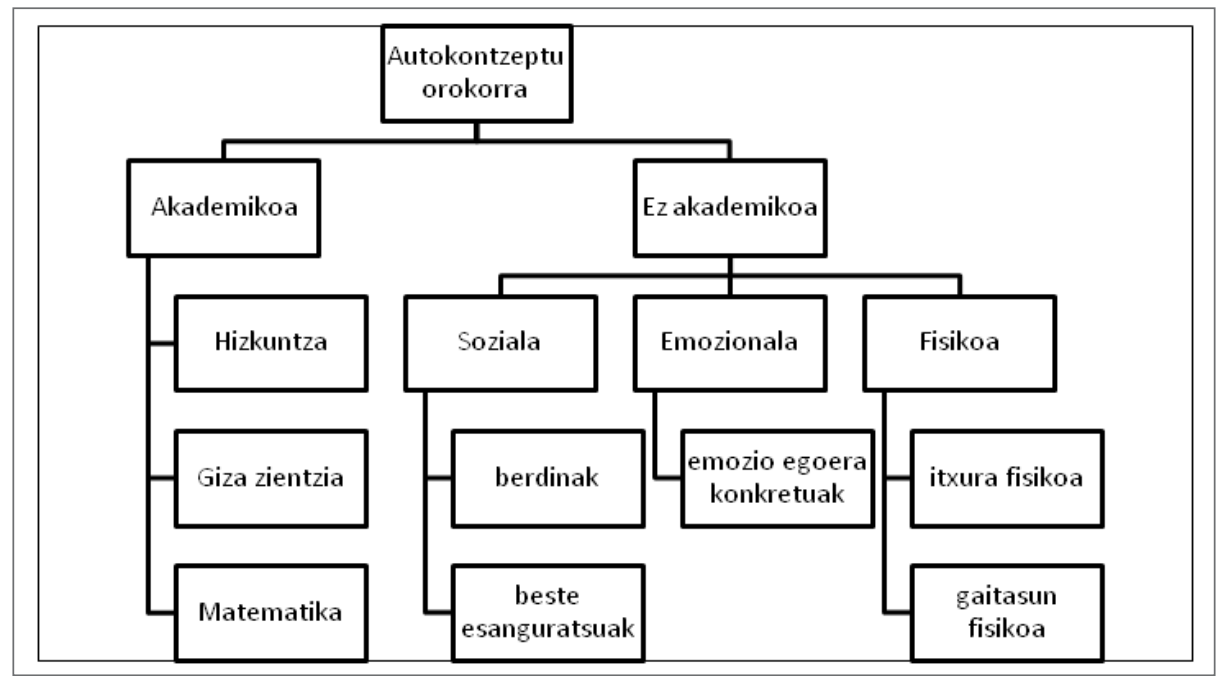

1.Irudia. Shavelson, Hubner \& Stantonen (1976) Autokontzeptu eredua.

\section{AUTOKONTZEPTU ARTISTIKOA}

Esnaolak, Goñik eta Madariagak (2008) proposamen iradokitzailea dela irizten diote Vispoel (1995) ikerlariak dantza, arte dramatikoa, arte plastikoa eta 
musikarako norberak dituen trebezien hautematean oinarrituriko azpi-eremuez osatutako eremu independientea izendatu izanari. Eremu honi Autokontzeptu Artistikoa deitu zion Vispoelek (1993) eta eremu artistikoan norberaren hautematea nolakoa den neurtzeko tresna psikometriko adierazgarrien gabezia aipatzen zuen. Hori horrela, Arts Self-Perception Inventory (ASPI) nerabeentzako dimentsioanitzeko neurtresna diseinatu zuen musika, ikusizko arteak, dantza eta arte dramatikoa eremuetan euren gaitasunen hautematea neurtzeko. Lehen ikerketa horretan, nerabeek lau eremu horietan zituzten gaitasunak ebaluatu eta bereizteko gai zirela zioten emaitzek. Faktoreen analisiak lau dimentsioak argi bereizi zituen eta dimentsioen fidagarritasuna altua zen (.92ko alpha de Cronbach indizea baino handiagokoak dimentsio guztietan); honez gain, ASPI eta aldagai independienteen (autokontzeptuaren beste dimentsioak adibidez) arteko korrelazioek konstruktu eredu logiko bat eratzen zuten neurtu nahi zuen. Emaitza hauek neurtresna balioztatzeko balio izan zuten eta Vispoelek helduentzako ASPla garatzen jarraitu zuen.

Bi urte beranduago, Vispoelek (1995), Shavelsonek, Hubner eta Staton. (1976) ikertutako ereduan, berak nerabeentzako neurtresnan izendatu zituen lau dimentsio berberak integratu zituen: musika, ikusizko arteak, dantza eta arte dramatikoa. 1993ko saiakeran zein arlo honetako beste ikerketetetan ez bezala (Marsh, 1987; Marsh eta Hocevar, 1985; Marsh eta Shavelson, 1985; Shavelson, Hubner eta Staton 1976), 1995ean eremu, dimentsio eta azpi dimentsio guztien arteko korrelazioak banaka aztertu zituen. Hala ere, emaitzek ez zuten ezberdintasun adierazgarririk erakutsi lau azpi-dimentsioen artean, ezta horietako bakoitzaren eta autokontzeptu artistikoaren artean ere.

\section{EGUNGO EGOERA}

Vispoelek diseinatutako galdetegia ez litzateke aztergai dugun laginaren testuinguruan erabilgarria, neurtu behar dituen aldagai psikoinstrukzionalak bi testuinguruetan ezberdinak baitira. ASPI neurtresna eredutzat hartuta, ordea, ikerketa honen lehen fasean Autokontzeptu Artistikoa neurtzeko tresna bat diseinatu da eta 397 norbanakok osaturiko laginarekin frogatu da. Barne egitura eta fidagarritasun emaitzak aztertu eta ikerketa zabaltzeko erabakia hartu da.

Gauzak horrela, autokontzeptu artistikoaren egitura identifikatu eta lau dimentsiotako egitura frogatzea helburua du ikerketa honek eta sexuaz, Unibertsitateaz eta espezialitateaz gain, kultura eta artearekiko interesa zein beste 
aldagaien arteko aldagaiek autokontzeptu artistikoarekin izan dezaketen harremana aztertzea.

\section{METODOA}

\section{PARTe-HARTZAileak}

Ikerketa honetan 1321 ikaslek hartu dute parte. Parte hartu duten Unibertsitateen artean bi pribatuak dira, Mondragon Unibertsitatea (\%33) eta Deusto Unibertsitatea (\%6) eta beste hirurak publikoak, Euskal Herriko Unibertsitatea (\%25), Begoñako Andra Mari (\%15) eta Cantabriako Unibertsitatea (\%21). Parte-hartzaileen artean Haur hezkuntzako Graduko ikasleak dira \%57 eta $\% 47$ Lehen hezkuntzako Gradukoak. Horien artean gehiengoa, \%75, emakumezkoak dira eta \%25 gizonezkoak.

Parte-hartzaileen aukeraketan irizpide nagusia EAEko Hezkuntza fakultate guztietako ikasleak izatea izan da. Cantabriako Unibertsitateko ikasleen aukeraketaren arrazoia egokiera izan da.

\section{Aldagaiak etA tRESNA}

Autokontzeptu artistikoa norberak dantzan, arte dramatikoan, musikan zein marrazketa eta pinturan bizi izandako esperientzia eta gaitasunetan oinarrituz eraikitako deskripzioa da eta lau aldagaik neurtzen dute: dantzak, dantzarako gaitasunen hautemateaz; arte dramatikoak, interpretazioan zein imitazioan hautemandako gaistasunen bidez; musikak, bere ekintzetarako hautemandako gaitasunen bitartez; eta marrazketa eta pinturak, euren ekintzetarako zein eskulturarako hautemandako gaitasunen bidez.

Autokontzeptu Artistikoaren Galdetegiaren (AUART) eraikitze prozesuan Vispoelen (1993), Self Perception Inventory (ASPI) for adults, Autore beraren (1993, 1994), Music Self Perception Inventory (MUSPI), Goñi, Ruiz de Azúa eta Rodríguez, (2008), autoreen Cuestionario de Autoconcepto Físico (CAF), Fernandezen (2011), Cuestionario de Autoconcepto Social (AUSO), Goñiren (2010), Cuestionario de Autoconcepto Personal (APE) eta Psikor ikertaldearen Dimentsioaniztun Autokontzeptuaren Neurgailua (AUDIM) ereduak aztertu 
dira. Batetik bostera bitarteko Likert eskalaren bidez neurtzeko galderek osatu dute galdetegi hau.

\section{Prozedura}

Datu bilketarako Unibertsitateetako irakasleekin harremana egin da eta zuzendaritzaren baimenak lortu dira. Galdetegia sarean jarri da eta galdera guztiei erantzutea bermatzeko baliabideak erabili dira, beraz, ez da datu galdurik izan.

Galdetegiaren bitartez eginiko datu bilketa anonimoa izan da eta galdetegiaren diseinua burututako autorearen eta irakasle laguntzaileen eskutik egin da 2011-2012, 2012-2013 eta 2013-2014 ikasturteetan.

\section{EMAITZAK}

\section{AUART GALDETEGIAREN EZAUGARRI PSIKOMETRIKOAK}

Autokontzeptu artistikoaren 4 dimentsioko egitura egiaztatzeko honako analisiak egin dira.

Deskribapen analisi bat egin da galdetegiko item bakoitzaren portaera ezagutu ahal izateko. Azterketa honen bitartez itemak diskriminazio gaitasuna duen eta bereiztu beharreko autopertzeptzio mailak ondo bereizteko gaitasuna duen jakin nahi da. Media zentratua (2 eta 4 artekoa) eta ohiko desbideratze altua ( 1 baino altuagoa) dituztela ikusi da eta, baita ere, asimetria balioak (1 eta -1 artekoak) eta kurtosi balioak (2 eta -2 artekoak) izateak, datuen banaketa uniformea bideratzen dutela.

Fidagarritasun analisiek eskalaren .840 puntuko Alpha Cronbachen balioa erakutsi dute. Dantzan.905 puntukoa, Antzerkian .785ekoa, Musikan .805ekoa eta Arte plastikoetan $.850 \mathrm{koa}$. Balio hauek ikerketan parte hartutako sujetuen inguruko erabaki hartzea bermatuko lukete (Pfeiffer, Heslin eta Jones 1976). Dantza faktorearen .913 balioak Streinerrek (2003) gomendatutako .90 balioaren gainetik erredundantzia erakutsi badu ere ez da alde adierazgarria. 
Faktoreen esplorazio analisiak itemen arteko harremana agerian jarri du eta korrelazioen matrizean taldekatzeak nabarmentzen ditu. KMO frogak $.860 \mathrm{ko}$ balioa erakutsi du eta eta Barlett frogak .000ko adierazgarritasuna. Hori horrela faktoreen analisia egin da eta aukeratze metodoa ardatz nagusien faktorizazioa izan da.

1. taula:

AUART galdetegiaren faktoreen esplorazio analisia

\begin{tabular}{|c|c|c|c|c|}
\hline & Dantza & Arte plastikoak & Musika & Antzerkia \\
\hline AUART05 & .868 & & & \\
\hline AUART01 & .834 & & & \\
\hline AUART10 & .809 & & & \\
\hline AUART15 & .777 & & & \\
\hline AUART24 & .679 & & & \\
\hline AUART12 & .584 & & & \\
\hline AUART13 & & .793 & & \\
\hline AUART17 & & .732 & & \\
\hline AUART20 & & .700 & & \\
\hline AUART04 & & .686 & & \\
\hline AUART08 & & .686 & & \\
\hline AUART09 & & .586 & & \\
\hline AUART23 & & & .702 & \\
\hline AUART07 & & & .671 & \\
\hline AUART03 & & & .661 & \\
\hline AUART11 & & & .579 & \\
\hline AUART18 & & & .573 & \\
\hline AUART19 & & & .541 & \\
\hline AUART06 & & & & .715 \\
\hline AUART22 & & & & .694 \\
\hline AUART21 & & & & .655 \\
\hline AUART16 & & & & .601 \\
\hline AUART14 & & & & .598 \\
\hline AUART02 & & & & .389 \\
\hline
\end{tabular}


Itemen pisu faktorial nagusiak argi ikusteko .300etik gorako balioak dira eta item guztiek bere eskalan erakutsi dute saturazio maila altuena.

\section{TALDEEN ARTEKO PUNTUAZiO EZBERdintAsunAK}

Ikerketaren bigarren helburuari erantzuteko AUART galdetegian lortutako puntuazioak alderatzeari ekin zaio. Bi kategorien arteko ezberdintasunak aztertzeko T-student froga burutu da, hala nola sexua (gizonezkoa edo emakumezkoa) eta ikasketen ibilbidea (haur hezkuntza edo lehen ezkuntza) aztertzeko. Bi kategoria baino gehiagoko konparaketak burutzeko ANOVA froga burutu da, adina, Unibertsitatea, ikasturtea eta kultura eta artearekiko duten interesaren araberako ezberdintasunak aztertzeko.

2. taula:

AUART eskalan sexu aldagaiaren araberako ezberdintasuna

\begin{tabular}{lllcccc}
\hline & \multicolumn{1}{c}{ Sexua } & $\mathbf{N}$ & $\begin{array}{c}\text { Batez- } \\
\text { bestekoa }\end{array}$ & $\begin{array}{c}\text { Ohiko } \\
\text { desbideratzea }\end{array}$ & t & p \\
\hline AUART Dantza & Gizonezkoa & 321 & 2.85 & .93 & -9.459 & $.000^{* * *}$ \\
& Emakumezkoa & 998 & 3.43 & .99 & & \\
AUART & Gizonezkoa & 321 & 2.92 & .74 & 4.615 & $.000^{* * *}$ \\
Antzerkia & & & & & & \\
& Emakumezkoa & 998 & 2.69 & .86 & & \\
AUART Musika & Gizonezkoa & 321 & 3.09 & .63 & -.100 & .920 \\
& Emakumezkoa & 998 & 3.10 & .61 & & \\
AUART Artplas & Gizonezkoa & 321 & 2.41 & .88 & -2.654 & $.008^{* *}$ \\
& Emakumezkoa & 998 & 2.56 & .99 & & \\
AUART TOTAL & Gizonezkoa & 321 & 2.82 & .52 & -3.719 & $.000^{* * *}$ \\
& Emakumezkoa & 998 & 2.95 & .53 & & \\
\hline
\end{tabular}

testua: ${ }^{*} p<.05 ;{ }^{* *} p<.01 ;{ }^{* * *} p<.001$

Goiko taulan agertzen den moduan emakumezkoek AUART eskalan lortutako puntuazioaren batezbestekoaren ezberdintasuna, gizonezkoek lortutakoarekin alderatuta adierazgarria da, Dantza eta Arte plastikoen dimentsioetan. Gizonezkoek antzerkian lortutako puntuazioaren batezbestekoa, emakumezkoenarekin alderatuta ere, adierazgarria da. AUART eskalan, osotasunean, emakumezkoek lortutako batezbesteko puntuazioa estatistikoki adierazgarria da. 
Haur hezkuntzako ibilbidekoek AUART eskalan lehen hezkuntzako ibilbidekoekin alderatuta, lortutako batazbesteko puntuazioen ezberdintasuna ere estadistikoki adierazgarria da, (Haur hezkuntza, $\mathrm{N}=745, \mathrm{~B}=2.94$, Ot $=.52786$, $\mathrm{t}=2.028$ eta $\mathrm{p}=.043^{*}$ eta Lehen hezkuntza, $\mathrm{N}=573, \mathrm{~B}=2.88$ eta $\mathrm{Ot}=.53750$ ).

Adinaren araberako ezberdintasun aipagarririk ez da ikusi, Antzerkiaren eskalan 36 urtetik gorakoek puntuazio ezberdintasun adierazgarria lortu badute ere $\left(\mathrm{N}=9, \mathrm{~B}=3.22\right.$, $\mathrm{Ot}=.78616, \mathrm{t}=2.225$ eta $\left.\mathrm{p}=.038^{*}\right)$. Kategoria honetan 9 subjektu bilzen dira, gutxi beste kategorietako kopuruarekin alderatuz gero, hori horrela, kasu batek eragindako ezberdintasuna izan daiteke.

Ikasturtearen araberako ezberdintasunei dagokienez estadistikoki adierazgarria da lehen mailakoen batezbestekoa. Musika eskalan ez beste guztietan ezberdintasun adierazgarria izaki, isla da eskalaren puntuazio orokorrean $\left(\mathrm{N}=534, \mathrm{~B}=2.99, \mathrm{Ot}=.53412, \mathrm{t}=6.571\right.$ eta $\left.\mathrm{p}=.000^{* * *}\right)$

Unibertsitateen araberako ezberdintasunak aztertzean arreta deitzen du Cantabriako Unibertsitateko ikasleek lortutako batezbesteko puntuazio ezberdintasunak. Estadistikoki adierazgarria da ezberdintasuna musika ez beste eskala guztietan eta hala du isla eskalaren puntuazio orokorrean ere $(\mathrm{N}=274, \mathrm{~B}=3.08$, Ot=.53719, $t=10.901$ eta $\left.p=.000^{* * *}\right)$.

Azkenik, ondorengo taulan ikus daitezkeen emaitzek, kultura eta artearekiko ikasleek duten interesaren araberako ezberdintasuna azaltzen dute: estadistikoki adierazgarria. Esanguratsua batezbesteko baxuena 1 eta 5 arteko likert eskalan $3 k o$ interes maila adierazi duten ikasleena izatea ere.

\section{3. taula:}

AUART eskalan kultura eta artearekiko interes aldagaiaren araberako ezberdintasuna

\begin{tabular}{lcccccc}
\hline & Ikasturtea & $\mathrm{N}$ & Batezbestekoa & $\begin{array}{c}\text { Ohiko } \\
\text { desbideratzea }\end{array}$ & $\mathrm{F}$ & $\mathrm{p}$ \\
\hline $\begin{array}{l}\text { AUART } \\
\text { Dantza }\end{array}$ & 1 & 51 & 3.4085 & 1.13838 & & \\
& 2 & 167 & 3.1512 & 1.01543 & & \\
& 3 & 325 & 3.0715 & .91579 & 12.048 & $.000^{* * *}$ \\
& 4 & 286 & 3.4277 & 1.00913 & &
\end{tabular}




\begin{tabular}{|c|c|c|c|c|c|c|}
\hline & 5 & 82 & 3.8049 & .97739 & & \\
\hline \multirow{5}{*}{$\begin{array}{l}\text { AUART } \\
\text { Antzerkia }\end{array}$} & 1 & 51 & 2.8301 & .89162 & & \\
\hline & 2 & 167 & 2.6687 & .90925 & & \\
\hline & 3 & 325 & 2.5840 & .78737 & 8.145 & $.000^{* * *}$ \\
\hline & 4 & 286 & 2.7823 & .81286 & & \\
\hline & 5 & 82 & 3.1382 & .85499 & & \\
\hline \multirow{5}{*}{$\begin{array}{l}\text { AUART } \\
\text { Musika }\end{array}$} & 1 & 51 & 3.0490 & .65089 & & \\
\hline & 2 & 167 & 3.0774 & .70494 & & \\
\hline & 3 & 325 & 2.9267 & .57396 & 12.810 & $.000^{* * *}$ \\
\hline & 4 & 286 & 3.1935 & .61262 & & \\
\hline & 5 & 82 & 3.4106 & .71155 & & \\
\hline \multirow{5}{*}{$\begin{array}{l}\text { AUART } \\
\text { Artplas }\end{array}$} & 1 & 51 & 2.3660 & .85636 & & \\
\hline & 2 & 167 & 2.3878 & .98985 & & \\
\hline & 3 & 325 & 2.3898 & .96063 & 6.187 & $.000^{* * *}$ \\
\hline & 4 & 286 & 2.5874 & .97279 & & \\
\hline & 5 & 82 & 2.9227 & 1.12923 & & \\
\hline \multirow{5}{*}{$\begin{array}{l}\text { AUART } \\
\text { TOTALA }\end{array}$} & 1 & 51 & 2.9135 & .50131 & & \\
\hline & 2 & 167 & 2.8213 & .58190 & & \\
\hline & 3 & 325 & 2.7430 & .44846 & 26.879 & $.000^{* * *}$ \\
\hline & 4 & 286 & 2.9977 & .49105 & & \\
\hline & 5 & 82 & 3.3191 & .47128 & & \\
\hline
\end{tabular}

\section{ONDORIOAK}

Lehen helburuari dagokionez, Autokontzeptu Artistikoaren egitura identifikatu eta lau dimentsiotako egitura frogatze bidean, eskalak barne egitura koherentea duela diote emaitzek eta fidagarritasun balio altuak lortu dira. Neurtresnaren balidazioari begira faktoreen konfirmazio analisiak burutu eta baliozkotasun ebidentziak lortzen diren ikusi behar da. 
Subjektu taldeen batazbesteko puntuazioen ezberdintasunek adierazten dutenak zera ondorioztatzera garamatza:

1. Emakumezkoek gizonezkoek baino autokontzeptu positiboagoa dutela.

2. Haur Hezkuntza Graduko ikasleek Lehen Hezkuntza Gradukoek baino autokontzeptu positiboagoa dutela . Honetan, lehen eta bigarren ondorio hauen harremana aipatu behar da. Haur hezkuntza graduko ikasleen gehiengoa emakumezkoa baita.

3. Adinaren araberako ezberdintasun estadistikoki adierazgarririk ez bada ere, lehen mailako ikasleen autokontzeptu artistikoa positiboa da modu adierazgarrian. Beraz, pentsa daiteke, adin tarte kategoriak osatzean banaketa zehatzagoa egiteak emaitza zehatzagoak eskaini diezazkigukela.

4. Unibertsitatearen araberako ezberdintasunen analisiek emaitza adierazgarriak eskaini dituzte Cantabriako Unibertsitateko ikasleen autokontzeptu artistiko positiboari dagokionez. Eskalaren baliokotasuna frogatzean, korrelazioen bitartez, aldagai gehiagorekin duen harremana aztertzean aterako dira ondorioak.

5. Subjetuak kultura eta artearekiko duen interesak harreman zuzena duela autokontzeptu artistikoarekin. Beraz neurtresna honen balidazio prozesuan aurrera egitearekin bat jarrerak neurtzeko pausuak ematea beharrezkoa dela ondorioztatzen da.

\section{Erreferenziak}

Aspy, David N., \& June H. Bulder. 1975. "The effect of teachers' inferred self concept upon student achievement". Journal of Educational Research 68: 386-9

Borden, George A. \& John D. Stone. 1982. La comunicación humana. Trad., Eddy Montaldo Buenos Aires: El Ateneo

Brookover, Wilbur B., Shailer Thomas \& Ann Paterson. 1964. "Self-concept of ability and school achievement". Sociology of Education 37: 271-8

Coopersmith, Stanley. 1967. The antecedents of self-esteem. San Francisco: Jossey-Bass

Esnaola Etxaniz, Igor, Alfredo Goñi Grandmontagne \& José María Madariaga Orbea. 2008. "EI autoconcepto: perspectivas de investigación". Revista de Psicodidáctica 131: 69-96 
Fernández Zabala, Aránzazu. 2011. "El autoconcepto social en la adolescencia y juventud: dimensiones, medida y relaciones”. Doktorego-tesia, Euskal Herriko Unibertsitatea. CD-ROM

Forte, Ellen E. \& Walter P. Vispoel. 1995. "Domain importance and involvement: relations between domain self-concepts and general self-esteem in preadolescence". Paper presented at the Annual Meeting of the American Educational Research Association (San Francisco, CA, April 18-22, 1995)

Goñi Grandmontage, Alfredo, Sonia Ruiz de Azúa García \& Arantzazu Rodríguez Fernández. 2006. Cuestionario de autoconcepto físico CAF. Madrid : EOS

Goñi Palacios, Eider. 2009. El autoconcepto personal: estructura interna, medida y variabilidad. Doktorego-tesia, Euskal Herriko Unibertsitatea. CD-ROM

Gouvêa Pimentel, Lucia. 2009. “¿Es o debe ser la disciplina artística eje esencial de los programas de formación a formadores en artes y educación artística?". Pensamiento, Palabra y Obra 2: $117-20$

Marsh, Herbert W. 1987. "The hierarchical structure of the self-concept: An application of hierarchical confirmatory factor analysis". Journal of Educational Measurement 24: 17-39

- 1990. "The structure of academic self-concept: The Marsh/Shavelson Model". Journal of Educational Psychology 82: 623-36

Marsh, Herbert W. \& Dennis Hocevar. 1985. "Application of confirmatory factor analysis to the study of self-concept: first- and higher order factor models and their invariance across groups". Psychological Bulletin 97(3): 562-82

Marsh, Herbert W. \& Richard J. Shavelson. 1985. "Self-concept: Its multifaceted, hierarchical structure". Educational Psychologist 20(3): 107-23

Marx, Ronald W. \& Philip H. Winne. 1978. "Construct interpretations of three self-concept inventories". American Educational Research Journal 15(1): 99-109

Naranjo Pereira, María Luisa. 2006. "El autoconcepto positivo: Un objetivo de la orientación y la educación". Actualidades Investigativas en Educación 6: 1-30

Pfeiffer, J. William, Richard Heslin \& John E. Jones. 1976. Instrumentation in human relations training. La Jolla, CA: University Associates

Rosenberg, Morris. 1965. Society and the adolescent self-image. Princeton, NJ: Princeton University

Shavelson Richard J., Judith J. Hubner \& Georges C. Staton. 1976. "Self-concept: Validation of construct interpretations". Review of Educational Research 46(3): 407-41

Streiner, David L. 2003. "Diagnosing tests: Using and misusing diagnostic and screening tests". Journal of Personality Assessment 81(3): 209-19

Vispoel, Walter P. 1993. "The development and validation of the arts self-perception inventory for adolescents". Journal of Educational Measurement 53(4): 1023-33

- 1995. "Self-concept in artistic domains: An extensión of the Shavelson, Hubner, and Stanton 1976 Model". Journal of Educational Psychology 87(1): 134-53

- 1996. The development and validation of the Arts Self-Perception Inventory for adults. Journal of Educational Measurement 56(4): 719-35 
Arau juridikoak

175/2007 DEKRETUA, urriaren 16koa, Euskal Autonomia Erkidegoko Oinarrizko Hezkuntzaren curriculuma sortu \& ezartzekoa (EHAA, 2007ko azaroak 13, asteartea)

365/2006 EBAZPENA, irailaren 26koa, Europar Parlamentuaren \& Kontseiluaren etengabeko formakuntzarako gomendio proposamenari Europar Parlamentuak emandako lege ebazpena (EBko Egunkari Ofiziala, 2006ko irailak 26, asteartea)

(Artículo recibido 30-04-15; aceptado 09-06-15) 